\title{
VARIAÇÃO NO USO DO PRESENTE DO MODO SUBJUNTIVO: INTEGRANDO NÍVEIS DE ANÁLISE
}

\author{
VARIATION IN THE USE OF PRESENT OF SUBJUNCTIVE: \\ INTEGRATING LEVELS OF ANALYSIS
}

\author{
Tatiana Schwochow Pimpão | Lattes | tatianapimpao@furg.br ${ }^{1}$ \\ Universidade Federal do Rio Grande
}

Resumo: A variação no uso do modo subjuntivo tem sido amplamente abordada, especialmente a partir da virada do século XXI, contribuindo com um importante mapeamento do fenômeno em dados de fala do português brasileiro. As pesquisas, muitas das quais ancoradas nos pressupostos da Teoria da Variação e Mudança, preocupam-se em controlar variáveis independentes na tentativa de identificar o contexto de retenção do subjuntivo e, por conseguinte, o contexto de entrada do modo indicativo. Independentemente das particularidades da amostra selecionada e dos procedimentos metodológicos adotados, os diferentes estudos realizados ressaltam a importância das variáveis tipo de oração e modalidade. No entanto, tais pesquisas não demonstram como o tipo de oração, situado no nível da sintaxe, está integrado ao nível discursivo-pragmático, âmbito da modalidade. Assim, este trabalho propõe incluir subtipos oracionais e proceder a um cruzamento de variáveis na tentativa de responder à seguinte questão: Como a variável de natureza sintática tipo de oração se articula com a variável de natureza discursivo-pragmática modalidade? Para responder a essa pergunta, recorre-se ao estudo de Pimpão (2012), que investigou o uso variável do presente do modo subjuntivo em dados de fala de informantes de Florianópolis e Lages (Projeto VARSUL). Resultados gerais apontam para a associação entre orações finais e submodo deôntico e entre orações causais, concessivas, condicionais, parentéticas e com o item talvez e o submodo epistêmico. Por sua vez, a oração substantiva objetiva direta exibe percentuais elevados sob o escopo do submodo deôntico, e a oração substantiva subjetiva, uso categórico de subjuntivo sob o escopo do submodo epistêmico.

Palavras-chave: Subjuntivo. Integração. Níveis de análise.

\footnotetext{
${ }^{1}$ Professora no Instituto de Letras e Artes da Universidade Federal do Rio Grande. Foi orientanda da professora Edair Maria Görski durante o mestrado (1997-1999) e o doutorado (2008-2012). De agosto de 2019 a junho de 2020, realizou estágio pós-doutoral sob supervisão da professora Edair. Deixa aqui registrado os mais sinceros agradecimentos pelo exemplo de atuação profissional.
} 
Abstract: The variation in the use of the subjunctive mood has been widely addressed especially since the turn of the 21 st century, contributing to a relevant mapping of the phenomenon in Brazilian Portuguese speech data. The research, frequently based on the assumptions of the Theory of Variation and Change, is concerned with independent variable controlling in an attempt to identify the context of retention of the subjunctive and, therefore, the context of entry in the indicative mood. Regardless the particularities of the selected sample and the methodological procedures adopted, different studies carried out emphasize the importance of the variables type of clause and modality. However, such research does not demonstrate how the type of clause, situated at the syntax level, is integrated with the discursive-pragmatic level, within the modality. Thus, this work proposes to include subtypes of clause and cross-tabulations variables in an attempt to answer the following question: How does the type of clause articulate with the discursive-pragmatic nature of modality? To answer this question, we use the work by Pimpão (2012), which investigated the variable use of the present of subjunctive in speech data from informants from Florianópolis and Lages (VARSUL Project). General results point to the association between purpose clauses and deontic submode and between causal, concessive, conditional, parenthetical clauses and clauses with the item talvez and the epistemic submode. In turn, the direct object noun clause displays high percentages under the scope of the deontic submode, and the subject clause and categorical use of subjunctive under the scope of the epistemic submode.

Keywords: Subjunctive. Integration. Levels of analysis.

\section{Introdução}

Estudos sobre o uso variável do modo subjuntivo têm recebido atenção de pesquisadores espalhados pelo Brasil. De forma geral, tais pesquisas tomam como referência um banco de dados já constituído, motivo pelo qual muitas estão centradas na análise de dados de informantes naturais de capitais. Como normalmente os bancos de dados abarcam cidades representativas do ponto de vista linguístico, os trabalhos podem, ainda, se dedicar a um falar de uma cidade específica, fora do eixo da capital, ou ainda propor análises comparativas. Menos frequentes são os estudos desenvolvidos a partir de amostras de escrita e de amostras constituídas pelo próprio pesquisador.

Esses diversos estudos já permitem um importante mapeamento do uso variável do modo subjuntivo do português do Brasil devido, em especial, à abrangência 
no território brasileiro e ao período de realização das pesquisas, que se intensificaram a partir da virada do século XXI (BOTELHO PEREIRA, 1974; WHERRITT, 1977; COSTA, 1990; ROCHA, 1997; PIMPÃO, 1999; ALVES NETA, 2000; GONÇALVES, 2003; GUIRALDELLI, 2004; SANTOS, 2005; MEIRA, 2006; CARVALHO, 2007; FAGUNDES, 2007; OLIVEIRA, 2007; VIEIRA, 2007; ALVES, 2009; ALMEIDA, 2010; BARBOSA, 2011; PIMPÃO, 2012).

No entanto, a interpretação dos resultados das pesquisas deve ser cautelosa, tendo em vista o objeto de análise e os procedimentos metodológicos adotados. $\mathrm{O}$ objeto de análise, ainda que contemple o modo subjuntivo, pode estar centrado em tempos verbais diferentes: presente, pretérito e futuro ou mesmo entre dois ou os três tempos verbais. Com relação à metodologia, os critérios são, em certa medida, particulares: (i) diferença nas variáveis independentes controladas, (ii) fatores que integram uma mesma variável, (iii) perfil social dos informantes, (iv) tamanho da amostra, (v) dados desconsiderados.

Essas especificidades não devem, porém, colocar em dúvida a contribuição das pesquisas. A cautela deve estar na análise comparativa entre os resultados, que precisa considerar as particularidades de cada trabalho. "Qualquer comparação de resultados deve observar rigorosamente o processo metodológico que envolve os estudos" (cf. PIMPÃO; GORSKI, 2020, p. 80). "Ainda assim, o mapeamento inicial permite um panorama muito interessante sobre o uso variável do modo subjuntivo e coloca em destaque algumas variáveis independentes, como modalidade e tipo de oração.” (PIMPÃO, 2015, p. 139).

Dentre os 18 trabalhos citados, 14 controlam a variável modalidade $e^{2}$ e 10 controlam o tipo de oração $o^{3}$. Dos demais 8 trabalhos que não controlam tipo de oração, 5 não o fazem por já delimitarem as orações substantivas como objeto de estudo (BOTELHO PEREIRA, 1974; ROCHA, 1997; GUIRALDELLI, 2004; CARVALHO, 2007; OLIVEIRA, 2007). É possível, no entanto, controlar subtipos de oração substantiva, conforme decisão metodológica de Vieira (2007), a despeito do próprio tipo de oração constituir objeto de análise (GONÇALVES, 2003; ALMEIDA, 2010). No entanto, o tipo de oração considerado para fins de discussão neste texto abrange outros contextos, para além das substantivas, como adjetivas e adverbiais, bem como orações parentéticas e orações com o item talvez ${ }^{4}$.

Essa breve apresentação do estado da arte das pesquisas desenvolvidas a partir de

\footnotetext{
2 Trabalhos que controlam modalidade: Costa (1990), Pimpão (1999), Alves Neta (2000), Gonçalves (2003), Guiraldelli (2004), Santos (2005), Meira (2006), Carvalho (2007), Fagundes (2007), Vieira (2007), Alves (2009), Almeida (2010), Barbosa (2011) e Pimpão (2012).

3 Trabalhos que controla tipo de oração: Wherritt (1977), Costa (1990), Pimpão (1999), Alves Neta (2000), Santos (2005), Meira (2006), Fagundes (2007), Alves (2009), Barbosa (2011) e Pimpão (2012).

${ }^{4}$ Tais contextos de análise serão ilustrados adiante.
} 
dados do português brasileiro pode ser assim sistematizada: (i) é crescente o interesse pelo estudo do uso variável do modo subjuntivo, em especial a partir da virada do século XXI; (ii) já há um significativo mapeamento do uso variável do modo subjuntivo, principalmente em amostras de dados de fala; (iii) as variáveis linguísticas modalidade e tipo de oração são controladas em muitos estudos, a despeito da constituição das amostras e de critérios metodológicos adotados; e (iv) análises comparativas são importantes desde que sejam relativizadas com base na consideração das especificidades de cada trabalho.

São inegáveis, portanto, as contribuições desses estudos para um panorama da variação no modo subjuntivo em dados de fala de informantes de diferentes localidades e como embasamento empírico para pensarmos sobre a intensidade da expansão do modo indicativo (CAMARA JR., 1986; PERINI, 2010) em contextos previstos, segundo gramáticas normativas, para o uso do subjuntivo (BECHARA, 2006; CEGALLA, 2007; CUNHA, 1992; CUNHA; CINTRA, 2007; MENDES DE ALMEIDA, 2005). No entanto, pelo menos uma questão parece permanecer em aberto: Como a variável de natureza sintática tipo de oração se articula com a variável de natureza discursivo-pragmática modalidade?

No intuito de responder a essa questão norteadora, tomamos como referência resultados da pesquisa de Pimpão (2012) acerca do uso variável do presente do modo subjuntivo em dados de fala de informantes naturais de Florianópolis e Lages ${ }^{5}$. Pretendemos alcançar os seguintes objetivos: (i) distribuir os tipos e subtipos de oração entre as modalidades epistêmica e deôntica e, a partir de então, (ii) explicitar a integração entre os níveis sintático e discursivo-pragmático com vistas a (iii) identificar contextos de maior e menor retenção do presente do modo subjuntivo.

Diante desse cenário, a organização deste texto parte, na primeira seção, de uma síntese das variáveis modalidade e tipo de oração, ilustradas por análise de exemplos da fala catarinense (PIMPÃO, 2012). Na segunda seção, são descritos os procedimentos metodológicos adotados. E, na terceira e última seção, explora-se a integração entre os níveis sintático e discursivo-pragmático a partir de um cruzamento entre ambas as variáveis, buscando atender os objetivos propostos. Seguem-se as considerações finais.

\section{Variáveis linguísticas}

Nesta seção, são recuperadas duas varáveis linguísticas controladas na pesquisa desenvolvida por Pimpão (2012), tipo de oração e modalidade. Para fins de alguma corre-

\footnotetext{
${ }^{5}$ Pimpão (2012) ainda investiga o uso variável do presente no modo subjuntivo em dados de escrita de jornais publicados nas cidades de Florianópolis e Lages.
} 
lação entre resultados, resultados quantitativos e interpretativos de outros estudos são considerados.

\subsection{Tipo de oração}

Para uma relativa comparação entre os resultados obtidos a partir do controle da variável linguística tipo de oração, foram consideradas cinco pesquisas: Costa (1990), Pimpão (1999), Alves Neta (2000), Santos (2005) e Pimpão (2012). Ainda que nem todas as pesquisas concentrem a investigação exclusivamente no uso variável do presente do subjuntivo e nem todas procedam a rodadas estatísticas e à análise dos mesmos ambientes sintáticos, todas apresentam resultados para a atuação da variável tipo de oração sobre esse tempo verbal. Todas também são conduzidas com base no aparato teórico-metodológico da Teoria da Variação e Mudança; e, em quatro, a variável tipo de oração obteve relevância estatística (ALVES NETA, 2000; SANTOS, 2005; PIMPÃO, 1999; 2012).

Como resultado da análise, observa-se que, em Costa (1990) e Alves Neta (2000), os percentuais para o uso do presente do subjuntivo são mais elevados nas orações substantivas, seguidos pelas orações adjetivas. Ainda em Costa (1990), as orações adverbiais atingem percentuais também elevados. Em Pimpão (1999), os percentuais que se destacam são encontrados nas orações substantivas e nas orações com o talvez, resultado parcialmente alcançado em Pimpão (2012).

Neste último estudo, o uso variável do presente do subjuntivo é controlado em duas amostras: em Florianópolis, as orações substantivas atingem um percentual mais elevado; em Lages, são as orações parentéticas e as orações com o item talvez. As orações substantivas atingem resultados mais altos também na pesquisa de Santos (2005). Com base nessas considerações gerais, e mesmo reconhecendo a particularidade da constituição dos bancos de dados e da metodologia, o ambiente sintático preferível ao uso do presente do modo subjuntivo está na oração substantiva.

Na pesquisa de Pimpão (2012), como nas demais, os contextos sintáticos correspondentes ao tipo de oração estão ancorados na previsão de gramáticas normativas quanto ao emprego do modo subjuntivo (BECHARA, 2006; CEGALLA, 2007; CUNHA, 1992; CUNHA; CINTRA, 2007; MENDES DE ALMEIDA, 2005). Esses gramáticos assinalam, de forma geral, que o subjuntivo deve ser empregado nas seguintes orações subordinadas: 
Orações substantivas sob o escopo de verbos, nomes ou expressões equivalentes que denotam desejo (01), manipulação (02), avaliação (03), probabilidade/crença (04), verdade (05):

(01) Ah, só ESPERO QUE o Brasil não PERCA hoje. Por causa do tempo, também, está mudando. (FLP 19, L129) ${ }^{6}$

(02) Ali, Deus o livre, ali a ordem que o general deu que eu sei, é que ali chegando uma criança ali, seja que hora que for, jeito que for, não é pra voltar. Não é pra voltar, é pra atender, sabe? A ordem do general é essa! Ele não QUER QUE nenhuma criança VOLTE pra casa. Chegou ali tem que internar e medicar, cuidar, né? (LGS 01, L918)7

(03) Não, aqui, nós visitamos geralmente o hospital Florianópolis, tem a Carmela Dutra, a Maternidade, né? Mas a gente entra facilmente, não tem problema nenhum. Inclusive eles GOSTAM QUE a gente VÁ fazer missa nos hospitais. (FLP 11, L227)

(04) Eu acho que sim. Só não acho, como tenho certeza, porque é uma coisa visível, né? Claro que a cidade em termos turísticos, em termos de afinidade financeira, eu ACREDITO QUE ela GANHA muito, por quê? Porque aqui Festa do Pinhão hoje se tornou uma festa até a nível nacional, né? (LGS 11, L446)

(05) E é o mundo inteiro, porque, na verdade, o combustível é que faz o movimento para o povo, né? Sem combustível o carro não sai do lugar, vamos dizer, não tem- Outra coisa é a parte do gás pessoal. Já BASTA QUE desde a lei já não ESTÁ tendo mais, né? Está muito pouco. (LGS 07, L394)

Orações adjetivas que expressam um fim ou uma consequência, um fato improvável (06), uma conjectura/hipótese (07);

(06) E um horário que em casa a gente não tem nada pra fazer, nem televisão, que televisão não se tira nada QUE PRESTA. (FLP 14, L299)

\footnotetext{
${ }^{6} \mathrm{O}$ código entre parênteses indica, respectivamente, a cidade (FLP para Florianópolis e LGS para Lages), o número da entrevista e a linha de onde o dado foi retirado.

${ }^{7}$ Os dados estão numerados de forma contínua, mesmo havendo repetição de alguns.
} 
(07) [... ] se precisar Deus me dá, assim como ele me ajudou essa vez, vai me ajudar mais vezes também, né? Ele vai me ajudar que eu vou arrumar um serviço assim mais calmo pra mim, né? um bom assim pra mim, né? QUE SEJA menos serviço, né? menos horas de serviço assim, né? (LGS 01, L1303)

Orações adverbiais, em que o subjuntivo, "em geral, não tem valor próprio. É um mero instrumento sintático de emprego regulado por certas conjunções" (CUNHA; CINTRA, 2007, p. 484). São estas as conjunções listadas pelos gramáticos: causais (não porque, não que), como em (08); concessivas (ainda que, embora, conquanto, posto que, se bem que, mesmo que, por muito que, por pouco que e semelhantes) ${ }^{8}$, como em (09); condicionais (contanto que, sem que, a não ser que, suposto que, caso, dado que), na expressão de uma hipótese ${ }^{9}$, como em (10); consecutivas, quando não exprimem um fato real, como em (11); finais (para que, a fim de que), como em (12); e temporais (antes que, até que, logo que), quando não codificam um fato real, como em (13).

(08) A minha de onze anos, eu tenho bem mais confiança de deixar a minha com ela, pra mim fazer as minhas vendas, do que com ela. NÃO É PORQUE eu não CONHEÇO, porque eu conheço, eu sei que ela é de família boa e tudo, é conhecida. Mas eu já acho a minha bem mais responsável do que ela, sabe? (LGS 02, L1272)

(09) E, eu ensinei meus filhos tudo o que- tudo o que eu aprendi dos meus pais, eu ensino para os meus filhos, né? APESAR DE QUE eles não LEVAM muito a sério, né? (LGS 09, L49)

(10) Da Farra-do-boi? Não tenho nada contra, DESDE QUE não MATE o boi, não FIRA o boi. (FLP 15, L585)

(11) Agora eu peguei essa menina pra cuidar dela, mas desde o dia que eu peguei ela, faz cinco dias que ela está aqui, eu ainda não pude dizer assim: "Hoje eu vou sair fazer uma venda e deixar ela sozinha com a menina”, não está dando.

\footnotetext{
${ }^{8}$ Bechara (2006, p. 282) destaca que não há "completo rigor a respeito" acerca do uso do subjuntivo sob o escopo de conjunções concessivas. Alinhado a esse pensamento, Mendes de Almeida (2005, p. 566) afirma o seguinte: "Era muito frequente entre os clássicos o indicativo, e ainda hoje é ele empregado quando se quer insistir no fato real: Ainda que a noite era de junho, não fazia apetecível a temperatura."

${ }^{9}$ No caso de orações condicionais, Bechara (2006, p. 282) ressalva que "se se tratar de coisa real ou tida como tal, geralmente aparece o indicativo".
} 
Ela não é responsável QUE DÊ pra- eu fico assim muito preocupada, sabe? quando eu saio. (LGS 02, L1263)

(12) Como por exemplo a abertura do prolongamento da Avenida Hercílio Luz, pra ligar a Avenida Hercílio Luz ao aterro da Baía Sul, Avenida Gustavo Richard, que por, sei lá, ou falta de sensibilidade do Ministério da Marinha, até hoje o Ministério da Marinha não liberou aquela área PRA QUE a Prefeitura POSSA abrir. (FLP 21, L5839)

(13) De todos os sonhos, eu quero conhecer um lugar. Entrevistador: Um lugar?

ANTES QUE eu MORRA, Bahia. (FLP 19, L943)

Orações com o item talvez não assinalam um uso exclusivo e obrigatório do modo subjuntivo, podendo o modo indicativo ser empregado. Nas palavras de Bechara (2006, p. 281), "parece que o indicativo deixa antever melhor a certeza de que o que se duvida se pode bem realizar".

(14) Olhar ainda vai, pra dar uma espiada, ainda vai. Pois é, TALVEZ eu não GOSTO, porque eu não aprendi a dançar, né? (FLP 10, L413)

(15) Eu gosto de estar no meio das pessoas, de eu sentir que eu estou sendo útil pra alguma coisa, entende? TALVEZ eu não FAÇA bem certo, mas eu tento, pelo menos, fazer. Não sei se meus alunos, talvez um dia eles vão pensar: "Não, quando eu estava lá em tal série.” TALVEZ um dia ENTRE na cabeça dele. Mas se não entrar, paciência. Eu pelo menos tentei, né? e eu acho que isso que importa. (LGS 18, L1346-1351)

Orações parentéticas equivalem às orações intercaladas, assim nomeadas por Mendes de Almeida (2005, p. 567): são orações que apresentam o emprego do subjuntivo "começadas por que, tomado substantivamente, quando limitam uma possibilidade: Que me LEMBRE, ele não disse isso (pelo que me lembro)”. Nas palavras de Bechara (2006, p. 283), "também têm o verbo no subjuntivo as orações introduzidas por que, quando restringem a generalidade de um asserto: Não há, que eu saiba, expressão mais suave." 
(16) Ah, mas, assim, o que mais me marcou, QUE eu me LEMBRO, foi isso, que foi muito engraçado. Da árvore, né? da árvore que a gente se jogava de uma pra outra e de King Kong que era muito engraçado. (FLP 01, L132)

(17) Aqui o nosso, aqui em Lages, pelo menos eu não vejo coisa assim, sabe? Que eu acho que é bem bom, o nosso aqui. $\mathrm{O}$ nosso aqui não tem problemas seríssimos assim, QUE eu SAIBA não, né? Que eu saiba não sei. (LGS 01, L993)

Todos esses trechos das entrevistas conduzidas com informantes de Florianópolis e de Lages ilustram, conforme mencionado, os contextos de emprego do modo subjuntivo de acordo com a perspectiva das gramáticas normativas (BECHARA, 2006; CEGALLA, 2007; CUNHA, 1992; CUNHA; CINTRA, 2007; MENDES DE ALMEIDA, 2005). São contextos de natureza sintático-semântica: valores nocionais estão associados a restrições sintáticas.

Certamente, nem sempre os usos reais, diretamente ancorados em uma situação comunicativa, correspondem à prescrição normativa. A gramática que se configura na negociação entre interlocutores orienta a própria interação ao mesmo tempo em que por ela é moldada. Por conseguinte, esse movimento pode fazer aflorar outras regras, outra relação entre subjuntivo e contexto sintático, conforme pode ser atestado pelos resultados apresentados na tabela a seguir.

Tabela 1 - Atuação da variável tipo de oração sobre o uso do presente do modo subjuntivo

\begin{tabular}{|l|c|c|c|c|c|c|}
\hline \multirow{2}{*}{ Contextos linguísticos } & \multicolumn{3}{|c|}{ Florianópolis } & \multicolumn{3}{c|}{ Lages } \\
\cline { 2 - 7 } & Freq./Total & \% & P.R. & Freq./Total & \% & P.R. \\
\hline Parentéticas & $04 / 07$ & 57 & 0,992 & $07 / 08$ & 87 & 0,989 \\
\hline Adverbiais & $33 / 62$ & 53 & 0,582 & $30 / 47$ & 63 & 0,603 \\
\hline Talvez & $18 / 33$ & 54 & 0,598 & $11 / 13$ & 84 & 0,625 \\
\hline Substantivas & $50 / 80$ & 62 & 0,411 & $58 / 78$ & 74 & 0,527 \\
\hline Adjetivas & $31 / 68$ & 45 & 0.363 & $36 / 82$ & 43 & 0,298 \\
\hline Total & $136 / 250$ & 54 & ------ & $142 / 228$ & 62 & ------ \\
\hline
\end{tabular}

Fonte: Pimpão (2012, p. 237).

Uma leitura geral dos resultados exibidos na Tabela 1 permite duas observações: (i) os percentuais são mais elevados na amostra de Lages e (ii) as orações adjetivas mostram- 
-se sensíveis ao uso do presente do indicativo, inibindo com mais força o presente do subjuntivo. Como hipótese explicativa, aventa-se a ausência de uma restrição sintática mais evidente nesse tipo de oração, diferentemente do que ocorre nas orações substantivas, com a presença de verbos e nomes da oração matriz; nas orações adverbiais, com a presença de conectores introdutores da oração subordinada; e com o próprio item talvez. No caso das parentéticas, a restrição sintática está no que, da mesma forma que nas adjetivas, porém, nas parentéticas, há um componente pragmático muito atuante: o cancelamento de uma inferência atribuída ao interlocutor (PIMPÃO, 2015).

De acordo com a Tabela 1, resultados percentuais colocam em destaque as orações substantivas (62\%) e as orações parentéticas (87\%) como contextos de retenção do presente do modo subjuntivo em Florianópolis e em Lages, respectivamente. Importa ressaltar, no entanto, o baixo número de dados de orações parentéticas. Esse tipo de oração parece ser bastante específico e não se mostra recorrente na amostra analisada. Os resultados encontrados na pesquisa de Pimpão (2012), especialmente quanto às orações substantivas, se alinham a resultados obtidos em outras pesquisas, que apontam para a sensibilidade do subjuntivo a esse tipo de oração (COSTA, 1990; ALVES NETA, 2000; FAGUNDES, 2007).

\subsection{Modalidade}

Conforme inicialmente destacado, a variável modalidade é controlada em diferentes pesquisas, ainda que os fatores que a compõem não sejam uniformes. A título de ilustração, citamos os estudos realizados por Fagundes (2007) e Pimpão (2012), que partem de uma olhar binário acerca da modalidade, considerando o eixo do conhecimento (epistêmico) e o eixo da conduta, do desejo (deôntico). Guiraldelli (2004), por sua vez, desprende o valor volitivo do eixo deôntico, seguindo uma orientação tripartida da modalidade: epistêmico, deôntico e volitivo. No estudo desenvolvido por Alves Neta (2000), a modalidade reúne quatro valores: volição, desejo, causa/necessidade e existência possível.

Ainda assim, como convergência de resultados alcançados em diferentes pesquisas, podemos destacar a associação entre verbos deônticos e/ou volitivos e o uso do subjuntivo, independentemente do(s) tempo(s) verbal(is) que constitui(em) objeto de estudo, das variáveis controladas e do número de ocorrências das amostras (cf. ALVES NETA, 2000; GONÇALVES, 2003; GUIRALDELLI, 2004; MEIRA, 2006; FAGUNDES, 2007; CARVALHO, 2007; VIEIRA, 2007; PIMPÃO, 1999, 2012). A maioria desses trabalhos, no entanto, controla a modalidade nas orações substantivas. 
Para amparar a concepção de modalidade, Pimpão (2012) recorre especialmente à literatura givoniana. Para Givón (2005, p. 149), “a atitude do falante não é apenas nem principalmente - sobre a proposição propriamente dita, mas sim sobre a atitude do ouvinte em relação à proposição assim como em relação ao falante" ${ }^{10}$. A consideração do componente pragmático coloca em realce a modalidade na negociação comunicativa, na interação falante-ouvinte. Givón (1995, p. 112) concebe dois tipos de atitudes/ julgamentos, o epistêmico e o deôntico, envolvendo as seguintes noções: "atitudes epistêmicas: verdade, crença, probabilidade, certeza, evidência e atitudes avaliativas: desejo, preferência, intenção, habilidade, obrigação, manipulação" ${ }^{11}$.

Vejamos alguns exemplos. Os dados de (18) a (20) situam-se no eixo epistêmico, responsável por codificar valores como probabilidade/crença e certeza, respectivamente.

(18) Pois olha, eu não sei. É, isso eu acho que vai ATÉ QUE ENTRE algum outro QUE VÊ que esse plano não está correto. É um que pode às vezes dar uma diferença, né? (LGS 07, L458-459)

(19) A minha vida mando eu, agora eu faço o que eu quero. Nem meus filhos eu não deixo me mandar, APESAR QUE o mais velho QUER mandar em mim, mas eu não deixo. (FPL 03, L438)

Com relação ao eixo deôntico, destacamos os seguintes valores: desejo, manipulação e avaliação, conforme ilustram, respectivamente, os dados a seguir ${ }^{12}$.

(20) Ah, só ESPERO QUE o Brasil não PERCA hoje. Por causa do tempo, também, está mudando. (FLP 19, L129) ${ }^{13}$

(21) Ali, Deus o livre, ali a ordem que o general deu que eu sei, é que ali chegando uma criança ali, seja que hora que for, jeito que for, não é pra voltar. Não é pra voltar, é pra atender, sabe? A ordem do general é essa! Ele não QUER QUE nenhuma criança VOLTE pra casa. Chegou ali tem que internar e medicar, cuidar, né? (LGS 01, L918)

10 (GIVÓN, 2005, p. 149): "The speaker attitude is, in turn, never just - not even primarily - about the proposition itself, but rather about the hearer's attitude toward the proposition as well as toward the speaker."

${ }^{11}$ (GIVÓN, 1995, p. 112): "Epistemic attitudes: truth, belief, probability, certainty, evidence. Valuative attitudes: desirability, preference, intent, ability, obligation, manipulation."

12 Os dados (20), (21) e (22) são, respectivamente, os dados (01), (02) e (03), recuperados do início do texto e renumerados.

13 O código entre parênteses indica, respectivamente, a cidade (FLP para Florianópolis e LGS para Lages), o número da entrevista e a linha de onde o dado foi retirado. 
(22) Não, aqui, nós visitamos geralmente o hospital Florianópolis, tem a Carmela Dutra, a Maternidade, né? Mas a gente entra facilmente, não tem problema nenhum. Inclusive eles GOSTAM QUE a gente VÁ fazer missa nos hospitais. (FLP 11, L227)

Nos resultados encontrados na pesquisa de Pimpão (2012), o presente do modo subjuntivo é mais provável de ocorrer em contexto de modalidade deôntica. A autora adota a terminologia submodo deôntico e submodo epistêmico, devido à subordinação de ambos os submodos à modalidade irrealis. Como Givón (1984, 1995, 2001, 2005) situa a modalidade na transação comunicativa, a relação entre os interlocutores é fundamental: tanto pelas condições do falante apresentar evidências sobre o que fala, quanto pelas condições do ouvinte refutar, questionar, aceitar a posição defendida pelo falante.

Encaixada no contexto comunicativo, a modalidade irrealis emerge quando a proposição é fracamente asserida, por ser possível, incerta, desejada. Como o falante não está preparado nem mesmo tem condições de sustentar sua asserção com evidências ou bases fortes, a contestação pelo ouvinte é natural e esperada e, de certa forma, prontamente recebida. Por essa razão, segundo Givón (1995, p. 123), "se o irrealis tem um denominador comum - incerteza epistêmica - então a marca gramatical compartilhada entre os dois submodos do irrealis torna-se não acidental" ${ }^{14}$.

A incerteza se faz presente tanto no eixo epistêmico, pelos valores de probabilidade e crença, quanto no eixo deôntico, com os valores de volição, manipulação e obrigação, que naturalmente projetam uma situação para um vir-a-ser, portanto, instaurando um ambiente de incerteza. Nesse sentido, os resultados encontrados na pesquisa de Pimpão (2012) estão alinhados à previsão givoniana, conforme pode ser observado a partir da interpretação dos resultados apresentados na tabela a seguir.

Tabela 2 - Atuação da variável submodo sobre o uso do presente do modo subjuntivo

\begin{tabular}{|l|c|c|c|c|c|c|}
\hline \multirow{2}{*}{ Submodo } & \multicolumn{3}{|c|}{ Florianópolis } & \multicolumn{3}{c|}{ Lages } \\
\cline { 2 - 7 } & Freq./Total & \% & P.R. & Freq./Total & \% & P.R. \\
\hline Deôntico & $46 / 67$ & 68 & 0,878 & $60 / 73$ & 82 & 0,783 \\
\hline Epistêmico & $90 / 183$ & 49 & 0,327 & $82 / 155$ & 52 & 0,354 \\
\hline Total & $136 / 250$ & 54 & ----- & $142 / 228$ & 62 & ------ \\
\hline
\end{tabular}

Fonte: Pimpão (2012, p. 237).

O percentual para o uso do presente do modo subjuntivo em contexto deôntico 
é mais elevado em Lages, se comparado ao resultado encontrado na fala de informantes de Florianópolis. O submodo epistêmico se apresenta como um ambiente que inibe o presente do subjuntivo, constituindo, portanto, contexto de entrada do presente do indicativo. Por outro lado, mesmo em contexto de alta certeza epistêmica, o presente do subjuntivo se faz atuante, conforme ilustra o dado (24).

(23) Olha, os idosos que residem aqui, eu tenho impressão assim que eles têm assim uma classe social pouquinho elevada, porque eles estão aqui, eles estão com uma mordomia muito grande, eles estão pagando essa mordomia, então eles têm um pouquinho de independência, não é? E eles estão aqui por opção deles, EMBORA ESTEJAM assim separados da família, mas foi uma opção deles. E tu sabes que o idoso, ele se discrimina, né? (FLP 22, L147)

O conector adverbial embora configura, nos termos de Bybee (BYBEE; PERKINS; PAGLIUCA, 1994), o modo subordinante. O modo subjuntivo é empregado em determinados tipos de oração subordinada sem que valores de incerteza estejam associados. O subjuntivo está, portanto, condicionado a determinados conectores. De acordo com Pimpão (2012, p. 307), “com relação ao valor 'certeza', surpreende que, na rodada com as ocorrências de Florianópolis, como mencionado, o presente do subjuntivo seja de uso categórico, inclusive nos contextos de 'certeza”. Em Lages, segue a autora, excetuando dois casos, "as demais ocorrências com o valor de 'certeza' são de uso categórico do presente do subjuntivo".

Diante do exposto sobre as duas variáveis, o contexto preferencial do presente do subjuntivo é este: em Florianópolis, submodo deôntico e orações substantivas; em Lages, submodo deôntico e orações parentéticas. No entanto, uma questão persiste, a questão norteadora deste trabalho: Como a variável de natureza sintática tipo de oração se articula com a variável de natureza discursivo-pragmática modalidade? O presente do subjuntivo se distribuiu igualmente em todos os tipos de oração substantiva? Em todos os tipos de oração adverbial?

\section{Procedimentos metodológicos}

$\mathrm{Na}$ tentativa de responder à questão norteadora deste trabalho, foram recuperados os dados investigados por Pimpão (2012). A autora analisou 24 entrevistas conduzidas com informantes naturais de Florianópolis e 24 com informantes naturais de Lages. As 
entrevistas compõem o banco de dados do Projeto VARSUL ${ }^{15}$. Os dados selecionados para análise consistem naqueles previstos por gramáticas normativas como sendo de emprego do subjuntivo (BECHARA, 2006; CEGALLA, 2007; CUNHA, 1992; CUNHA; CINTRA, 2007; MENDES DE ALMEIDA, 2005).

Foram recuperadas codificações, e os dados foram submetidos a uma nova rodada estatística, de modo que fosse possível cruzar os submodos deôntico e epistêmico com os tipos e os subtipos de oração. Nesse sentido, dentre as orações substantivas, foram controlados os seguintes subtipos: objetiva direta, objetiva indireta, subjetiva, completiva nominal, apositiva. As orações adverbiais incluem causal, concessiva, condicional, consecutiva, final, modal, e temporal. A apresentação e a análise dos resultados estão na seção seguinte.

\section{Integrando níveis de análise}

A integração dos níveis sintático e discursivo-pragmático, traduzidos neste trabalho por meio das variáveis tipo de oração e modalidade, põe em destaque tipos/subtipos oracionais que ocorrem sob o escopo de um ou outro submodo. De forma geral, as pesquisas controlam o tipo de oração como variável independente. A título de ilustração, diferentes estudos têm apontado as orações substantivas como um contexto de retenção do subjuntivo (COSTA, 1990; ALVES NETA, 2000; FAGUNDES, 2007). No entanto, não se pode afirmar que os subtipos desse tipo de oração apresentariam o mesmo resultado para subjuntivo. Essa observação também se aplica ao contexto das orações adverbiais: o subjuntivo não atinge o mesmo percentual em todos os subtipos oracionais. O controle dos subtipos oracionais é menos frequente e, quando ocorre, legitima-se por propiciar uma investigação mais detalhada do próprio tipo de oração (VIEIRA, 2007).

Nesse sentido, uma análise mais atenta aos subtipos oracionais pode contribuir com uma maior compreensão do uso variável do presente do subjuntivo, especialmente se o nível sintático estiver integrado ao discursivo-pragmático, tratado neste trabalho a partir dos submodos deôntico e epistêmico. Assim posto, isolar os subtipos das orações substantivas e das orações adverbiais pressupõe refinar a análise e o poder explicativo do fenômeno. Por outro lado, o número de ocorrências diminui, tendo em vista que as subdivisões aumentam. Nesse cenário, emerge a relevância de interpretações qualitativas.

Inicialmente, apresentamos o cruzamento de duas variáveis: subtipos oracionais e

\footnotetext{
${ }^{15}$ Informações sobre o Projeto VARSUL podem ser acessadas no site: www.varsul.org.br.
} 
o submodo deôntico.

Tabela 3 - Subtipos de oração sob o escopo do submodo deôntico e o uso do presente do modo subjuntivo

\begin{tabular}{|l|c|c|c|c|}
\hline \multirow{2}{*}{$\begin{array}{c}\text { Tipos e subtipos } \\
\text { de oração }\end{array}$} & \multicolumn{4}{c|}{ Submodo deôntico } \\
\cline { 2 - 5 } & \multicolumn{2}{|c|}{ Florianópolis } & \multicolumn{2}{c|}{ Lages } \\
\cline { 2 - 5 } & Freq./Total & $\%$ & Freq./Total & $\%$ \\
\hline Final & $\mathbf{0 5 / 0 5}$ & $\mathbf{1 0 0}$ & $\mathbf{0 5} / \mathbf{0 5}$ & $\mathbf{1 0 0}$ \\
\hline Completiva nominal & $\mathbf{0 3 / 0 3}$ & $\mathbf{1 0 0}$ & $\mathbf{0 3} / \mathbf{0 3}$ & $\mathbf{1 0 0}$ \\
\hline Objetiva indireta & $\mathbf{0 1 / 0 1}$ & $\mathbf{1 0 0}$ & $\mathbf{0 4} / \mathbf{0 4}$ & $\mathbf{1 0 0}$ \\
\hline Temporal & $\mathbf{0 1 / 0 1}$ & $\mathbf{1 0 0}$ & $\mathbf{0 / 0 2}$ & $\mathbf{0}$ \\
\hline Modal & $\mathbf{0 1 / 0 1}$ & $\mathbf{1 0 0}$ & $\mathbf{0 1} / \mathbf{0 1}$ & $\mathbf{1 0 0}$ \\
\hline Objetiva direta & $27 / 36$ & 75 & $25 / 27$ & 93 \\
\hline Adjetiva & $07 / 15$ & 47 & $13 / 20$ & 65 \\
\hline Subjetiva & $01 / 05$ & 20 & $08 / 10$ & 80 \\
\hline Apositiva & $\mathbf{0 / 0}$ & $\mathbf{0}^{16}$ & $\mathbf{0 1} / \mathbf{0 1}$ & $\mathbf{1 0 0}$ \\
\hline
\end{tabular}

Fonte: Elaborado pela autora.

Com base nos resultados exibidos na Tabela 3, o presente do subjuntivo apresenta uso categórico nos seguintes contextos oracionais e em ambas as cidades: adverbial final, substantiva completiva nominal, substantiva objetiva indireta e adverbial modal (destacados em negrito). O uso categórico do presente do subjuntivo em contexto de adverbial temporal somente ocorre nos dados de Florianópolis, e, em contexto de substantiva apositiva, nos dados de Lages (cf. destaques em negrito). Os demais subtipos já apresentam uso variável: substantiva objetiva direta, adjetiva e substantiva subjetiva.

O gráfico a seguir exibe os percentuais em ordem decrescente, tendo como referência os resultados alcançados para os dados de fala dos informantes naturais de Florianópolis.

${ }^{16}$ Os resultados apresentados nas Tabelas 3 e 4 seguem a ordem decrescente, tendo a cidade de Florianópolis como parâmetro. 
Gráfico 1 - Resultados percentuais referentes aos subtipos de oração sob o escopo do submodo deôntico e o uso do presente do modo subjuntivo

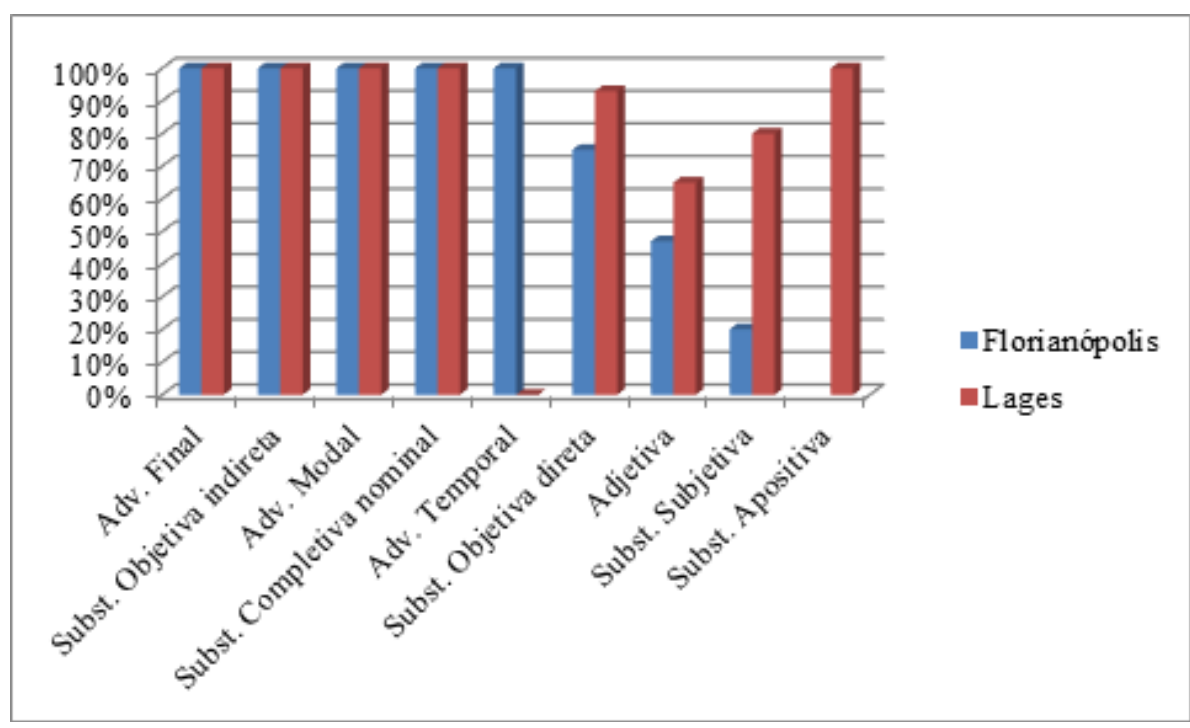

Fonte: Elaborado pela autora.

A distribuição dos resultados percentuais no gráfico permite uma visualização ao mesmo tempo mais concreta e panorâmica do funcionamento do uso variável do presente do subjuntivo. Para uma análise qualitativa, desconsiderarei dois subtipos devido ao número de ocorrências: adverbial modal e adverbial apositiva. Os usos categóricos de presente do subjuntivo ocorrem nas orações adverbiais final e temporal e nas orações substantivas objetiva indireta e completiva nominal. Constituem contextos de variação as orações substantivas objetiva direta e subjetiva e as orações adjetivas. Trataremos desses tipos oracionais a seguir.

As orações adverbiais finais, conforme ilustrado em (24), constituem ambientes do submodo deôntico devido à força manipulativa do agente da oração matriz em relação à situação expressa na oração subordinada, constituindo um ambiente muito favorável à retenção do subjuntivo. É um tipo de oração cuja "restrição semântica na oração matriz não depende da ação, mas sim da escolha e do controle"17 (GIVÓN, 1990, p. 837). Quando posposta à matriz, a oração subordinada claramente codifica a intenção do agente da oração matriz em promover a realização da ação (GIVÓN, 1990; 2001). Isso porque a posição da oração subordinada em relação à oração matriz contribui para uma maior ou menor força expressiva. O exemplo (24) ilustra esse cenário, na medida em que assinala a força do Ministério da Marinha no controle da abertura de uma determinada área pela Prefeitura. 
(24) Como por exemplo a abertura do prolongamento da Avenida Hercílio Luz, pra ligar a Avenida Hercílio Luz ao aterro da Baía Sul, Avenida Gustavo Richard, que por, sei lá, ou falta de sensibilidade do Ministério da Marinha, até hoje o Ministério da Marinha não liberou aquela área PRA QUE a Prefeitura POSSA abrir. (FLP 21, L5839)

No que diz respeito às orações temporais, Palmer (1986) prevê um uso frequente do subjuntivo em orações temporais que codificam situações hipotéticas futuras ao passo que o indicativo é esperado na codificação de situações referidas no passado. Nos dados em análise, situações futuras são esperadas, tendo em vista o emprego do modo subjuntivo, como ilustra o dado (25). O dado (26), por sua vez, já assinala uma situação não projetada para o futuro; antes, uma situação espraiada no tempo, contemplando passado, presente e futuro.

(25) De todos os sonhos, eu quero conhecer um lugar.

Entrevistador: Um lugar?

ANTES QUE eu MORRA, Bahia. (FLP 19, L943)

(26) Agora, hoje em dia não, mas eles cortam gila e depois cozinha assim, os pedaços grandes, daí tiram tudo da casca, daí espreme bem ela, aquela água que tem, né? coloca na panela, coloca açúcar, vai mexendo ATÉ QUE FICA no ponto, né? no ponto do doce. (LGS 08, L152)

Nos casos das orações substantivas objetiva direta, objetiva indireta e completiva nominal, importa considerar o verbo ou o nome presente na oração matriz. São os verbos e os nomes que colocam sob seu escopo a situação codificada na oração subordinada. Givón (2001) considera três grupos: verbos de modalidade (querer, desejar, esperar), como nos exemplos (01) e (02); verbos de manipulação (fazer com que) e verbos de percepção, cognição ou enunciação ${ }^{18}$. A oração subjetiva, por sua vez, apresenta um comportamento bastante peculiar, muito próximo ao que Bybbee, Perkins e Pagliuca (1994) definem como modo subordinante. Nas palavras de Givón (2005, p. 166),

em espanhol e outras línguas, a forma do subjuntivo pode invadir um

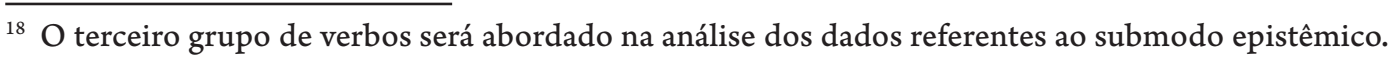


domínio modal adjacente, o afeto intensificado. O contexto gramatical para esse aspecto é, à primeira vista, de alguma forma contraditório, estando sob o escopo de predicados factivos. Assim posto, são predicados cujos complementos verbais são pressupostos ${ }^{19}$.

(27) É, então vai diminuindo, uns vão vendendo, né? a maioria vende. Ih! conheço muita gente aí que- Filhos [de]- fazendeiros fortes que hoje alguns até não têm nem uma casa pra morar aí, aqui em Lages. É BOM QUE GRAVEM isso, porque é uma verdade. (LGS 23, L824)

O dado (27) ilustra uma situação prevista por Bybbee, Perkins e Pagliuca (1994) Givón (2005). O presente do subjuntivo está sob o escopo de um predicado factivo e encaixado em uma situação apresentada como real, tendo em vista que a gravação mencionada pelo informante está em curso no momento de sua fala.

Vejamos os resultados para os subtipos oracionais associados ao submodo epistêmico.

Tabela 4 - Subtipos de oração sob o escopo do submodo epistêmico e o uso do presente do modo subjuntivo

\begin{tabular}{|c|c|c|c|c|}
\hline \multirow{3}{*}{$\begin{array}{l}\text { Tipos e subtipos } \\
\text { de oração }\end{array}$} & \multicolumn{4}{|c|}{ Submodo epistêmico } \\
\hline & \multicolumn{2}{|c|}{ Florianópolis } & \multicolumn{2}{|c|}{ Lages } \\
\hline & Freq./Total & $\%$ & Freq./Total & $\%$ \\
\hline Subjetiva & 08/08 & 100 & $10 / 10$ & 100 \\
\hline Condicional & $09 / 10$ & 90 & $01 / 01$ & 100 \\
\hline Temporal & $02 / 03$ & 67 & $01 / 01$ & 100 \\
\hline Concessiva & $11 / 29$ & 62 & $14 / 27$ & 52 \\
\hline Parentéticas & 04/07 & 57 & $07 / 08$ & 88 \\
\hline Talvez & $18 / 33$ & 55 & $11 / 13$ & 85 \\
\hline Completiva nominal & $01 / 02$ & 50 & $04 / 04$ & 100 \\
\hline Adjetiva & $24 / 53$ & 45 & $23 / 62$ & 37 \\
\hline Objetiva direta & $09 / 25$ & 36 & $03 / 19$ & 16 \\
\hline Causal & $04 / 13$ & 31 & 07/09 & 78 \\
\hline Consecutiva & $\mathbf{0} / \mathbf{0}$ & $\mathbf{0}$ & $01 / 01$ & 100 \\
\hline
\end{tabular}

Fonte: Elaborado pela autora.

Na comparação com os resultados da tabela anterior, a Tabela 4 exibe apenas dois casos de uso categórico: substantiva subjetiva para ambas as cidades e adverbial consecutiva para os dados de Lages (destaques em negrito). Nos demais casos, ainda que haja uso 
categórico de presente do subjuntivo para ocorrências de Lages, Florianópolis já apresenta uso variável para o presente do subjuntivo. Essa leitura inicial dos resultados destaca o submodo deôntico como um importante contexto de retenção do presente do subjuntivo (cf. Tabela 3), seguindo a previsão de Givón (1995) e seguindo resultados de diferentes estudos (cf. ALVES NETA, 2000; GONÇALVES, 2003; GUIRALDELLI, 2004; MEIRA, 2006; FAGUNDES, 2007; CARVALHO, 2007; VIEIRA, 2007; PIMPÃO, 1999, 2012). Os subtipos oracionais situados no submodo epistêmico tendem a apresentar um espectro percentual mais fluido para o uso do presente do subjuntivo (cf. Tabela 4).

O gráfico, a seguir, exibe os percentuais em ordem decrescente, tendo como referência os resultados alcançados para os dados de fala dos informantes naturais de Florianópolis.

Gráfico 2 - Resultados percentuais referentes aos subtipos de oração sob o escopo do submodo epistêmico e o uso do presente do modo subjuntivo

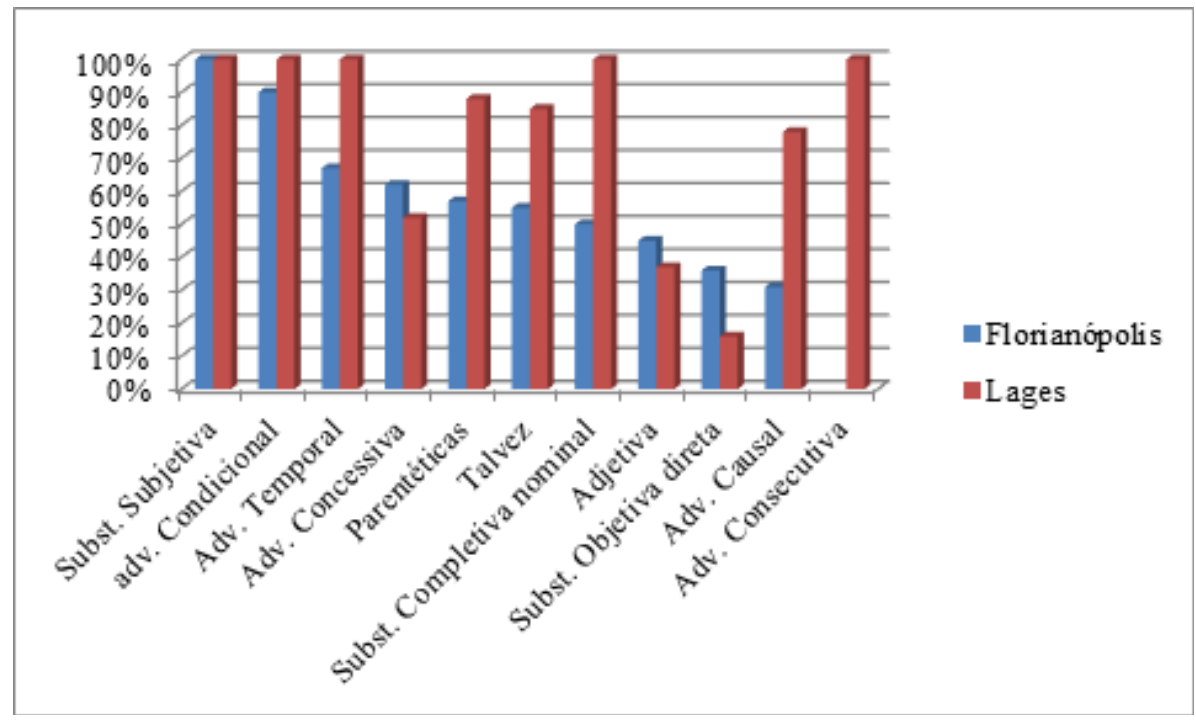

Fonte: Elaborado pela autora.

Dentre os subtipos oracionais, destacaremos, para fins de análise, as orações adverbiais ${ }^{20}$ condicional, concessiva e causal, por serem específicas do submodo epistêmico, e a oração substantiva subjetiva objetiva direta, por envolver um grupo específico de verbos na oração matriz: verbos de percepção, cognição e enunciação.

Para Givón (1990, p. 829), as orações condicionais irrealis

se enquadram no escopo da modalidade não-fato. Muito parecido com

\footnotetext{
${ }^{20}$ Excluiremos da análise a oração adverbial consecutiva devido a apresentar um único dado em toda a
} amostra. 
outras cláusulas irrealis, elas "não têm valor de verdade". Em vez disso, sua verdade depende da verdade da oração matriz - que normalmente também não tem valor de verdade. Normalmente, as cláusulas condicionais irrealis têm uma futuridade implícita, com a própria oração matriz marcada por um operador de futuro, operador modal ou algum outro operador irrealis ${ }^{21}$.

O dado (28) ilustra um contexto de oração adverbial com uma projeção futura da situação codificada na oração subordinada.

(28) Da Farra-do-boi? Não tenho nada contra, DESDE QUE não MATE o boi, não FIRA o boi. (FLP 15, L585)

Na perspectiva de Givón (1990, p. 835), orações adverbiais concessivas "envolvem um contraste pressuposto ou contraexpectativa, com a cláusula ADV fornecendo os motivos para a contraexpectativa, e a oração matriz fornecendo o evento ou estado inesperado ou menos provável $^{22}$. Pimpão (2012) destina uma seção de sua pesquisa para reunir tipos oracionais que compartilham de uma propriedade bastante específica: a de atenuar/corrigir uma inferência atribuída ao ouvinte ou por ele manifestada. O exemplo (29) parece indicar que o informante, ao introduzir a oração concessiva, cancela uma inferência atribuída ao entrevistador. Provavelmente, com receio de que o entrevistador suponha que seus filhos aprendem tudo que lhes é ensinado, o informante faz uma ressalva.

(29) E, eu ensinei meus filhos tudo o que- tudo o que eu aprendi dos meus pais, eu ensino para os meus filhos, né? APESAR DE QUE eles não LEVAM muito a sério, né? (LGS 09, L49)

No caso das orações causais, Givón (2001, p. 335) estabelece uma diferença entre causa e razão: a causa envolve "algum fator externo que impele o agente a agir ou causa um estado de tornar-se"23; a razão, por sua vez, envolve um fator externo ou mesmo um

\footnotetext{
${ }^{21}$ (GIVÓN, 1990, p. 829): "Irrealis conditional clauses fall under the scope of the non-fact modality. Much like other irrealis clauses, they 'have no truth value'. Rather, their truth depends on the truth of their associated main clause - which most typically has no truth value either. Typically, irrealis conditional clauses have an implied futurity, with the main clause itself marked by either future, or modal or some other irrealis operator."

${ }^{22}$ (GIVÓN, 1990, p. 835): “[... ] involve a presupposed contrast or counter-expectancy, with the ADVclause supplying the grounds for the counter-expectation, and the main clause supplying the unexpected or less-likely event or state."

23 (GIVÓN, 2001, p. 335): "Some external factor either impels an agent to act, or causes a state to become." e "has a reason for acting, speaking or thinking in a particular way."
} 
falante que "tem uma razão para agir, falar ou pensar de uma maneira particular". Givón (2001) não apresenta exemplos semelhantes ao (30)

(30) A minha de onze anos, eu tenho bem mais confiança de deixar a minha com ela, pra mim fazer as minhas vendas, do que com ela. NÃO É PORQUE eu não CONHEÇO, porque eu conheço, eu sei que ela é de família boa e tudo, é conhecida. Mas eu já acho a minha bem mais responsável do que ela, sabe? (LGS 02, L1272)

A oração causal em (30) assume a mesma propriedade da oração concessiva ilustrada em (29), a de cancelar uma inferência atribuída ao interlocutor. Ainda que Givón (2001) não apresente exemplos semelhantes, a diferenciação que estabelece entre causa e razão parece ser bastante apropriada. Com base no dado em análise, o informante parece ter uma razão para falar/usar a oração adverbial causal, tendo em vista que se vale de um recurso sintático com finalidade pragmática.

Por fim, o submodo epistêmico abarca casos de oração substantiva objetiva direta sob escopo de verbos de cognição, como em (31).

(31) Eu acho que sim. Só não acho, como tenho certeza, porque é uma coisa visível, né? Claro que a cidade em termos turísticos, em termos de afinidade financeira, eu ACREDITO QUE ela GANHA muito, por quê? Porque aqui Festa do Pinhão hoje se tornou uma festa até a nível nacional, né? (LGS 11, L446)

Como análise geral, importa destacar que certos tipos oracionais mostram-se específicos de um e outro submodo, e outros subtipos oracionais estão presentes tanto no submodo deôntico quanto no submodo epistêmico. Os resultados apresentados nas tabelas 3 e 4 indicam que tipos/subtipos oracionais ocorrem somente sob o escopo de um e outro submodo. Sob o escopo do submodo deôntico, estão as orações adverbiais finais e modais, bem como as orações objetivas indiretas e apositivas. Sob o escopo do submodo epistêmico, estão as orações adverbiais condicionais, concessivas, causais, consecutivas, bem como as orações parentéticas e as orações com o item talvez. Os demais contextos oscilam entre os submodos deôntico e epistêmico.

Ainda, chamamos atenção de dois subtipos em especial: oração objetiva direta e 
subjetiva. A oração substantiva objetiva direta sob o escopo do submodo deôntico apresenta percentuais elevados para o uso do presente do subjuntivo: 75\% em Florianópolis e 93\% em Lages. Sob o escopo do submodo epistêmico, os percentuais diminuem significativamente: $36 \%$ para os dados de Florianópolis e 16\% para os de Lages. Por sua vez, a oração substantiva subjetiva sob escopo do submodo deôntico apresenta percentuais opostos para o uso do subjuntivo considerando ambas as cidades: $20 \%$ e $80 \%$, respectivamente. Diferentemente, o submodo epistêmico constitui contexto de uso categórico de presente do subjuntivo em dados de ambas as cidades.

Isso posto, afirmar que o subjuntivo é provável de ocorrer em contexto de oração substantiva constitui uma informação importante, porém não toda a informação. Da mesma forma, afirmar que o presente do subjuntivo mostra-se menos frequente no ambiente sintático de oração adverbial não permite inferir um contexto de entrada do presente do indicativo. Vale destacar que o subjuntivo é de uso categórico nas orações finais e exibe percentuais mais baixos sob o escopo de conectores concessivos (62\% nos dados de Florianópolis e 52, nos de Lages). Explorar a análise, refinando as variáveis, permite reconhecer um outro cenário: determinados tipos de oração estão associados ao submodo deôntico; outros, ao submodo epistêmico; outros ainda, associados a ambos.

\section{Considerações finais}

Retomemos a pergunta norteadora deste trabalho: Como a variável de natureza sintática tipo de oração se articula com a variável de natureza discursivo-pragmática modalidade? A variável tipo de oração abriga diferentes subtipos, que podem apresentar um comportamento diferenciado. Isso foi observado nos contextos de oração substantiva e de oração adverbial. A compreensão da distribuição dessas orações torna-se mais efetiva se considerados os subtipos oracionais. Percebemos, assim, que o submodo, variável de natureza discursivo-pragmática, identifica-se com determinados subtipos, como a oração adverbial final, associada ao submodo deôntico, e a oração adverbial concessiva, vinculada ao submodo epistêmico. Por sua vez, as orações substantivas objetiva direta e subjetiva se manifestam sob o escopo de ambos os submodos.

A consideração da variável discursivo-pragmática propiciou uma maior compreensão dos ambientes sintáticos listados nas gramáticas normativas como de emprego do subjuntivo. Ainda, contribuiu com uma análise mais refinada desses ambientes sintáticos a partir da investigação mais detalhada dos subtipos oracionais, o que normalmente, por motivos de tempo e espaço, não é contemplado nas pesquisas com dados do português 
do Brasil. Certamente, o refinamento da análise qualitativa implicou uma diminuição no número de dados para cada subtipo, no entanto, acreditamos em uma terceira contribuição deste estudo: sugerir um olhar mais cauteloso para resultados de pesquisas que correlacionam o uso variável do subjuntivo a contextos sintáticos.

\section{Referências}

ALMEIDA, E. S. de. Variação de uso do subjuntivo em estruturas subordinadas: do século XIII ao XX. 2010. 294f. Tese (Doutorado em Letras Vernáculas) - Faculdade de Letras, Universidade Federal do Rio de Janeiro, Rio de Janeiro, 2010.

ALVES NETA, A. O uso de formas do indicativo por formas do subjuntivo no português brasileiro. 2000. 114f. Dissertação (Mestrado em Letras: Linguística) - Faculdade de Letras, Universidade Federal de Minas Gerais, Belo Horizonte, 2000.

ALVES, R. F. A expressão de modalidades típicas do subjuntivo em duas sincronias do português: séculoXVI e contemporaneidade. 2009.197f. Tese (Doutorado em Linguística) - Instituto de Estudos da Linguagem, Universidade Estadual de Campinas, Campinas, 2009.

BARBOSA, A. F. Alternância de formas indicativas e subjuntivas na fala de Vitória (ES). 2011. 146f. Dissertação (Mestrado em Linguística) - Universidade Federal do Espírito Santo, Vitória, 2011.

BECHARA, E. Moderna gramática portuguesa. 37. ed. (revista e ampliada). Rio de Janeiro: Lucerna, 2006.

BOTELHO PEREIRA, M. A. Aspectos da oposição modal indicativo/subjuntivo no português contemporâneo. 1974. 265f. Dissertação (Mestrado em Língua Portuguesa) Universidade Federal do Rio de Janeiro, Rio de Janeiro, 1974.

BYBEE, J.; PERKINS, R.; PAGLIUCA, W. The evolution of grammar: tense, aspect, and modality in the languages of the world. Chicago: The University of Chicago press, 1994.

CAMARA JR., J. M. Dicionário de linguística e gramática. 13. ed. Petrópolis: Vozes, 1986.

CARVALHO, H. M. de. A alternância indicativo/subjuntivo nas orações substantivas em função dos tempos verbais presente e imperfeito na língua falada do Cariri. 2007. 158f. Tese (Doutorado em Linguística) - Departamento de Letras Vernáculas, Universidade Federal do Ceará, Fortaleza, 2007.

CEGALLA, D. P. Novíssima gramática da língua portuguesa. 46. ed. São Paulo: Companhia Editora Nacional, 2007.

COSTA, I. B. O verbo na fala de camponeses: um estudo de variação. 1990. 223f. Tese (Doutorado em Linguística) - Instituto de Estudos da Linguagem, Universidade Estadual de Campinas, Campinas, 1990.

CUNHA, C. Gramática da língua portuguesa. Rio de Janeiro: FAE, 1992.

CUNHA, C.; CINTRA, L. Nova gramática do português contemporâneo. 4. ed. Rio de 
Janeiro: Lexikon Editora Digital, 2007.

FAGUNDES, E. D. As ocorrências do modo subjuntivo nas entrevistas do VARSUL no estado do Paraná e as possibilidades de variação com o modo indicativo. 2007. 220f. Tese (Doutorado em Letras) - Ciências Humanas, Letras e Artes, Universidade Federal do Paraná, Curitiba, 2007.

GIVÓN, T. Context as other minds: the pragmatics of sociality, cognition and communication. Amsterdam/Philadelphia: John Benjamins, 2005.

GIVÓN, T. Functionalism and grammar. Amsterdam/Philadelphia: John Benjamins, 1995.

GIVÓN, T. Syntax: a functional-typological introduction. Amsterdam/Philadelphia: John Benjamins, vol. I, 1984.

GIVÓN, T. Syntax: a functional-typological introduction. Amsterdam/Philadelphia: John Benjamins, vol. II, 1990.

GIVÓN, T. Syntax: an introduction. Amsterdam/Philadelphia: John Benjamins, vols. I e II, 2001.

GONÇALVES, J. R. Considerações sobre a flutuação no emprego do subjuntivo em contextos orais do Português do Brasil.2003. 100f.Dissertação (Mestrado em Letras) - Departamento de Letras, Pontifícia Universidade Católica, Rio de Janeiro, 2003.

GUIRALDELLI, L.A. O modo subjuntivo e a expressão das modalidades epistêmica, deôntica e volitiva. 2004. 104f. Dissertação (Mestrado em Estudos Linguísticos) - Instituto de Biociências, Letras e Ciências Exatas, Universidade Estadual Paulista, São José do Rio Preto, 2004.

MEIRA, V. O uso do modo subjuntivo em orações relativas e completivas no português afrobrasileiro. 2006. 317f. Dissertação (Mestrado em Letras e Linguística) - Instituto de Letras, Universidade Federal da Bahia, Salvador, 2006.

MENDES DE ALMEIDA, N. Gramática metódica da língua portuguesa. 45. ed. São Paulo: Saraiva, 2005.

OLIVEIRA, M. do C. de. O uso do modo verbal em estruturas de complementação no português do Brasil. 2007. 155f. Dissertação (Mestrado em Linguística) - Instituto de Letras, Universidade de Brasília, Brasília, 2007.

PALMER, F. Mood and modality. Cambridge: Cambridge University Press, 1986.

PERINI, M. Gramática do português brasileiro. São Paulo: Parábola, 2010.

PIMPÃO, T. S. Mapeamento do uso variável do modo subjuntivo no português do Brasil. In: Working Papers em Linguística, 16(1): 120-141, Florianópolis, jan. / jul., 2015.

PIMPÃO, T. Pressuposição e a variação no presente do modo subjuntivo. Letrônica, 8(2), 376-390. 2015.

PIMPÃO, T. Uso variável do presente do modo subjuntivo: uma análise de amostras de 
fala e escrita das cidades de Florianópolis e Lages nos séculos XIX e XX. 2012. 350f. Tese (Doutorado em Linguística) - Centro de Comunicação e Expressão, Universidade Federal de Santa Catarina, Florianópolis, 2012.

PIMPÃO, T. Variação no presente do modo subjuntivo: uma abordagem discursivopragmática. 1999. 129f. Dissertação (Mestrado em Linguística) - Centro de Comunicação e Expressão, Universidade Federal de Santa Catarina, Florianópolis, 1999.

PIMPÃO, T.; GÖRSKI, E. M. Interpretação qualitativa de resultados quantitativos: uma análise do processo metodológico na comparação de diferentes pesquisas. Working Papers em Linguística, Florianópolis, n. 1, p. 71-81. 2010.

ROCHA, R. C. A alternância indicativo/subjuntivo nas orações subordinadas substantivas em português. 1997. 125f. Dissertação (Mestrado em Linguística) - Departamento de Linguística, Línguas Clássicas e Vernáculas, Universidade de Brasília, Brasília, 1997.

SANTOS, R. M. A. dos. O uso variável do modo subjuntivo em estruturas complexas. 2005. 170f. Dissertação (Mestrado em Estudos Linguísticos) - Instituto de Biociências, Letras e Ciências Exatas, Universidade Estadual Paulista, São José do Rio Preto, 2005.

VIEIRA, M. M. M. Alternância no uso dos modos indicativo e subjuntivo em orações subordinadas substantivas: uma comparação entre o português do Brasil e o francês do Canadá. 2007. 106f. Dissertação (Mestrado em Letras) - Departamento de Letras, Universidade Federal do Rio Grande do Norte, Natal, 2007.

WHERRITT, I. M. The subjunctive in Brazilian Portuguese. 1977. 191f. Tese (Doutorado em Filosofia) - Department of Modern and Classical Languages, University of New Mexico, Albuquerque, 1977.

Data de submissão: 21/09/2020

Data de aceite: $21 / 01 / 2021$

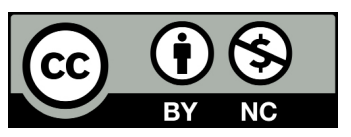

